\title{
Human epithelial ovarian cancer cells expressing CD105, CD44 and CD106 surface markers exhibit increased invasive capacity and drug resistance
}

\author{
JIN ZHANG ${ }^{1}$, BAOZHU YUAN ${ }^{2}$, HUIDAN ZHANG ${ }^{3}$ and HONGXIA LI ${ }^{1}$ \\ ${ }^{1}$ Department of Obstetrics and Gynaecology, Beijing Shijitan Hospital, Capital Medical University, Beijing 100038; \\ ${ }^{2}$ Cell Collection and Research Centre, National Institutes for Food and Drug Control, Beijing 100050; \\ ${ }^{3}$ Department of Gynaecology, Beijing Maternal and Child Health Hospital of Haidian District, Beijing 100080, P.R. China
}

Received December 27, 2017; Accepted February 14, 2019

DOI: $10.3892 / \mathrm{ol} .2019 .10221$

\begin{abstract}
The high rate of mortality associated with ovarian cancer (OC) is due in part to the development of resistance to chemotherapy, which allows the resistant tumour cells to invade and metastasise. Clarifying the mechanistic basis for drug resistance may reveal novel avenues for treatment. The present study investigated the mechanism of paclitaxel (PTX) resistance in human epithelial OC by evaluating the expression of stem cell-associated cell surface markers endoglin (CD105), CD44 antigen and vascular cell adhesion molecule 1 (CD106), in association with the malignant potential of the human OC OVCAR3 cell line and its PTX-resistant derivative OC3/TAX300. The expression of CD105, CD44 and CD106 was detected by reverse transcription quantitative polymerase chain reaction (RT-qPCR) and flow cytometry, and cell invasion was evaluated using a Transwell invasion assay. CD105, CD44 and CD106 levels were increased in OC3/TAX300 cells compared with the OVCAR3 cells, as determined by flow cytometry $(\mathrm{P}<0.01)$ and RT-qPCR $(\mathrm{P}<0.05)$. Additionally, the number of invading cells was increased in the OC3/TAX300 group compared with the OVCAR3 group $(54.7 \pm 6.65$ vs. $31.8 \pm 6.55 ; \mathrm{P}<0.01)$. A western blot analysis of cell surface marker expression in 80 clinical epithelial OC tissue samples, differing in terms of sensitivity to drug treatments, disease stage and degree of differentiation, revealed that high CD105, CD44 or CD106 expression was associated with drug resistance, advanced disease stage, poor differentiation and high rate of recurrence. These data indicated that exposure to high doses of PTX enhanced the stem-like properties of OC cells,
\end{abstract}

Correspondence to: Professor Hongxia Li, Department of Obstetrics and Gynaecology, Beijing Shijitan Hospital, Capital Medical University, 10 Tieyi Road, Haidian, Beijing 100038, P.R. China

E-mail: lihx6260@163.com

Key words: endoglin, ovarian cancer, cancer stem cells, paclitaxel resistance, cell invasion which are associated with drug resistance and invasion and lead to poor prognosis due to induced chemoresistance and/or metastasis. Therefore, CD105, CD44 and CD106 may serve as potential stem cell-associated cell surface and prognostic markers, and therapeutic targets, in OC.

\section{Introduction}

Ovarian cancer (OC) has one of the highest mortality rates among all gynaecological malignancies (1). Paclitaxel (PTX) combined with platinum is the standard chemotherapy regimen for OC. However, treatment failure may occur due to the development of PTX resistance, along with invasion and metastasis of tumour cells.

In cases of resistance, a subset of the tumour cell population exhibits inherited or acquired drug resistance and therefore survives chemotherapy, resulting in tumour recurrence (2). These drug-resistant cells are considered to be cancer stem cells (CSCs), which are responsible for poor prognosis in patients with cancer (3-5). CSCs have the capacity for unlimited proliferation, self-renewal and multilineage differentiation, and may also avoid the effects of chemotherapy, leading to local invasion and distant metastasis. Therefore, an ideal strategy for preventing tumour recurrence is one that targets CSCs (6). In addition, clarifying the mechanisms of action for drug resistance may reveal novel avenues for treatment.

OC is heterogeneous (7), and the tumours contain subpopulations of cells with SC characteristics (8). A number of these subpopulations have been identified, including those positive for CD44 antigen (CD44) and prominin 1 (CD133) (9-11). Cultured epithelial ovarian adenocarcinoma ascite cells have been revealed to exhibit self-renewal and long-term proliferative potential, which is associated with the overexpression of typical CSC markers, including CD44 (12). Recurrent tumours have been demonstrated to exhibit a larger fraction of CSCs expressing aldehyde dehydrogenase 1 family member A1, CD44 and CD133 compared with matched primary OC specimens. Furthermore, several genes involved in SC maintenance, including endoglin (CD105), are upregulated in residual tumour cells in samples from relapsed patients at the end of primary therapy (2), suggesting that resistant tumours 
overexpress SC genes. Cells expressing the mesenchymal SC marker CD105 isolated from human renal carcinoma samples and CD105-positive cells and clones derived from renal carcinoma samples are enriched in tumour-initiating cells with SC characteristics (13). Vascular cell adhesion molecule 1 (CD106) is a surface marker expressed by mesenchymal and neural SCs $(14,15)$ that is associated with OC metastasis and recurrence (16). All of these factors are associated with the self-renewal, chemoresistance and metastasis of cancer cells and may be CSC surface markers. However, to the best of our knowledge, the significance of CD105, CD44 and CD106 as CSC markers in OC has not been investigated previously.

We previously established the PTX-resistant OC OC3/TAX300 cell line with a resistance index of 6.70 by exposing OVCAR3 cells to PTX (17). We hypothesised that resistance to PTX treatment leads to an enrichment of the CSC population in OC cells, with increased expression of SC surface markers including CD105. To examine this hypothesis, the present study analysed the expression of CD105 and other SC surface markers, including CD44 (2) and CD106 (16), in OC3/TAX300 cells and clinical OC tissue samples that were graded in terms of the degree of malignancy in our previous study (7). The invasiveness and metastatic potential of PTX-resistant OC3/TAX300 cells was also evaluated, and the association between the clinical features of the tumours and the expression of SC factors was examined.

\section{Materials and methods}

Ethics statement. The present study was approved by the Ethics Committee of the Beijing Shijitan Hospital of Capital Medical University (Beijing, China). Written informed consent was obtained from all participants prior to surgery. All procedures were performed in accordance with the Declaration of Helsinki.

Cell lines and culture conditions. The OVCAR3 cell line was provided by the Basic Medical Research Institute (Beijing, China) and has been described in other studies $(18,19)$. The PTX-resistant OC3/TAX300 cell line used was previously established (17). Cells were cultured in RPMI-1640 medium (Gibco; Thermo Fisher Scientific, Inc., Waltham, MA, USA) supplemented with $10 \%$ bovine calf serum (BCS; Beijing Dingguo Changsheng Biotechnology Co., Ltd., Beijing, China), $0.1 \%$ penicillin and $0.1 \%$ streptomycin at $37^{\circ} \mathrm{C}$ in an environment containing $5 \% \mathrm{CO}_{2}$.

Reagents and antibodies. TRIzol ${ }^{\circledR}$ reagent and primers were obtained from Invitrogen (Thermo Fisher Scientific, Inc.). Dimethyl sulfoxide was purchased from Sigma-Aldrich; Merck KGaA (Darmstadt, Germany). Microplates were purchased from Beijing Dingguo Changsheng Biotechnology Co., Ltd. Mouse monoclonal anti-human CD105 (cat. no. 14606), CD44 (cat. no. 3570) and CD106 (cat. no. 3565) antibodies were purchased from Cell Signalling Technology, Inc. (Danvers, MA, USA).

Flow cytometry analysis of CD105, CD44 and CD106 expression. OVCAR3 and OC3/TAX300 cells in the logarithmic phase were collected and washed twice with PBS.
The cells were resuspended in PBS at a concentration of $1 \times 10^{6} / \mathrm{ml}$, and a $100-\mu 1$ suspension was incubated with $5 \mu 1$ PerCP-Cy5.5-conjugated anti-CD105, phycoerythrin-conjugated anti-CD44 or fluorescein isothiocyanate-conjugated anti-CD106 antibodies (BD Biosciences, San Jose, CA, USA) for $1 \mathrm{~h}$ at $37^{\circ} \mathrm{C}$. The cells were washed twice with PBS and analysed with a FACSCalibur flow cytometer (FlowJo 7.6.1; BD Biosciences).

Reverse transcription quantitative polymerase chain reaction (RT-qPCR) analysis. Total RNA was extracted from cells using TRIzol reagent, according to the manufacturer's protocol and reverse transcribed using moloney murine leukemia virus reverse transcriptase, $5 \mathrm{X}$ first strand buffer (dithiothreitol), $10 \mathrm{mM}$ deoxynucleotide triphosphates, Oligo (dT)18 (all from Tiangen Biotech Co., Ltd., Beijing, China). The temperature protocol used for RT was $42^{\circ} \mathrm{C}$ for $50 \mathrm{~min}$ and $95^{\circ} \mathrm{C}$ for $5 \mathrm{~min}$. Primers targeting CD105, CD44 and CD106 genes were designed according to sequence data obtained from GenBank (20), with $\beta$-actin (ACTB) used as an internal control. The primer sequences were as follows: CD105, 5'-GCCAAGGGCAACTGTGTGA-3'(sense) and 5'-CCGGTT TTGGGTATGGGTACT-3' (antisense); CD44, 5'-CCTCTT GGCCTTGGCTTTG-3' (sense) and 5'-CTCCATTGCCAC TGTTGATCAC-3' (antisense); CD106, 5'-TGGTCAGCCCTT CCTCCAT-3' (sense) and 5'-AGGATTTTCGGAGCAGGA AAG-3' (antisense); and ACTB, 5'-AGGTCACCATTGGCA ATG-3' (sense) and 5'-GGTAGTTTCGTGGATGCCACA-3' (antisense). The cDNA was amplified using SYBR Green PCR Master Mix (Applied Biosystems; Thermo Fisher Scientific, Inc.) and the thermocycling conditions were as follows: $50^{\circ} \mathrm{C}$ for $2 \mathrm{~min}, 95^{\circ} \mathrm{C}$ for $10 \mathrm{~min}$, then 40 cycles of $95^{\circ} \mathrm{C}$ for $15 \mathrm{sec}$ and $60^{\circ} \mathrm{C}$ for $1 \mathrm{~min}$ for the amplification curve and $95^{\circ} \mathrm{C}$ for $15 \mathrm{sec}$, $60^{\circ} \mathrm{C}$ for $15 \mathrm{sec}$ and $95^{\circ} \mathrm{C}$ for $15 \mathrm{sec}$ for the dissociation curve. Data were analysed using Sequence Detection Software V2.2 (Applied Biosystems; Thermo Fisher Scientific, Inc.) and exported to an Excel spreadsheet (Microsoft Corporation, Redmond, WA, USA). Target gene expression levels were normalised to that of ACTB. The mRNA expression ratio of CD105, CD44 or CD106 to ACTB was calculated to obtain relative expression values using the formula: $\Delta \mathrm{Cq}=\mathrm{Cq}$ (target gene)-Cq (ACTB); where $\mathrm{q}$ is the number of cycles when the DNA concentration reached the threshold (21).

Invasion assay. The invasive capabilities of OVCAR3 and OC3/TAX300 cells were assessed using a Transwell assay. Cells in the logarithmic phase were collected and washed with PBS, and then cultured in serum-free medium for $24 \mathrm{~h}$. In total, $40 \mu \mathrm{l}$ Matrigel was coated on the membrane of the upper chamber surface and incubated at $37^{\circ} \mathrm{C}$ for $30 \mathrm{~min}$ to solidify. The cells were then collected, and their concentration was adjusted to $1 \times 10^{5}$ cells $/ \mathrm{ml}$; they were then seeded in the upper chamber of a 24-well Transwell insert coated with a thin layer of Matrigel (BD Biosciences). The lower chamber was filled with RPMI-1640 medium supplemented with $20 \%$ BCS. The cells were incubated at $37^{\circ} \mathrm{C}$ and $5 \% \mathrm{CO}_{2}$. After $24 \mathrm{~h}$, cells remaining in the upper chamber were scraped off along with the Matrigel using a sterile swab, and cells that had invaded into the insert were fixed with $40 \mathrm{~g} / 1$ paraformaldehyde for $20 \mathrm{~min}$ at room temperature and stained with $0.01 \%$ crystal 

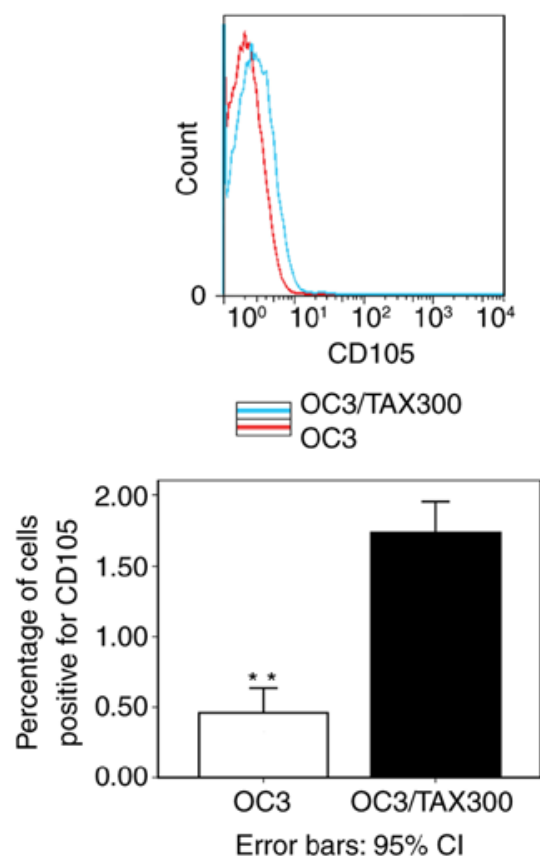
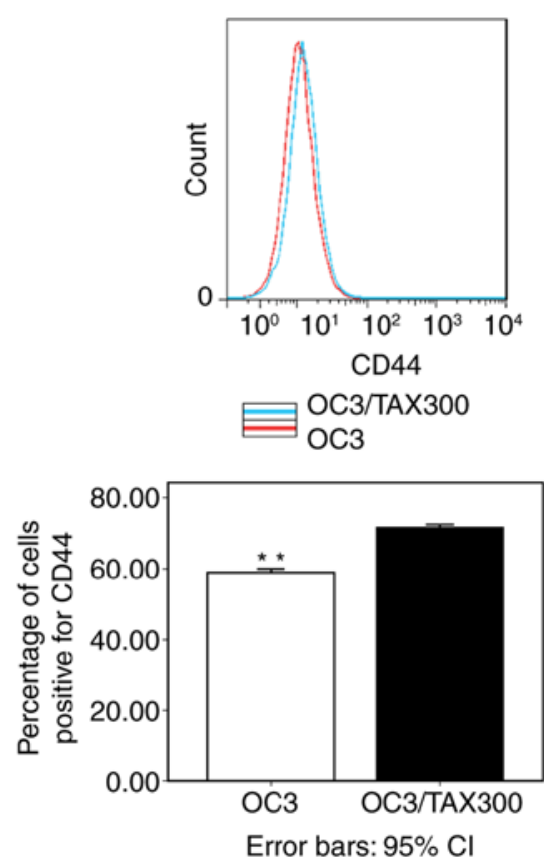
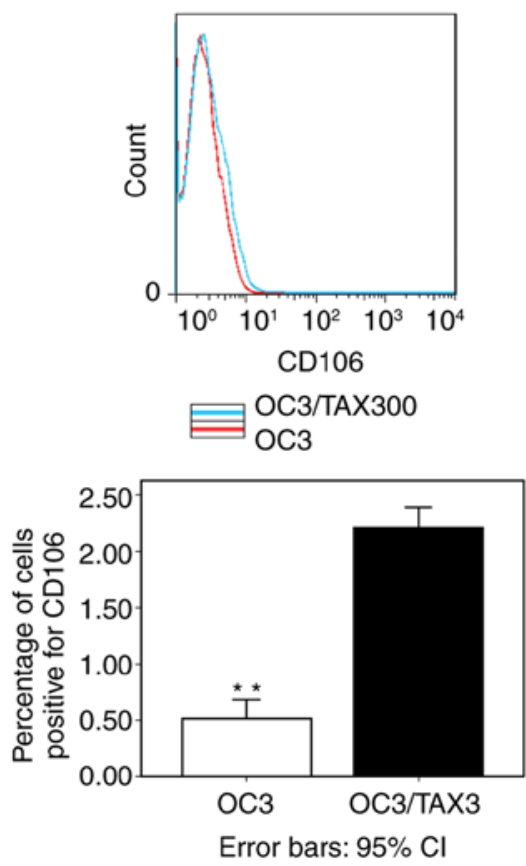

Figure 1. Quantitative analysis of OC3/TAX300 and OVCAR3 cells positive for CD105, CD44 and CD106 detected by flow cytometry. The fraction of cells positive for the 3 markers was increased in the PTX-resistant OC3/TAX300 cell line compared with the PTX-sensitive OVCAR3 cell line. ${ }^{* *}$ P $<0.01$. PTX, paclitaxel; CD44, CD44 antigen; CD105, endoglin; CD106, vascular cell adhesion molecule 1; CI, confidence interval.

violet for $20 \mathrm{~min}$ at room temperature for observation by light microscopy (magnification, $x 40$ ). Images of cells in at least five randomly selected microscopic fields were captured and the number of cells was counted. The average number of cells was used to assess the invasive capacity of the 2 cell lines.

Clinical OC samples. A total of 80 epithelial OC tissue samples were collected from the specimen repository of Beijing Shijitan Hospital between April 2012 and February 2013 (7). The median age of the patients was 56.15 years (range, 23-79 years). There were 52 primary and 28 recurrent cases; 64 were poorly differentiated and 16 were moderately or highly differentiated OC tissue; and 63 samples were advanced-stage (III) whereas 17 were early-stage (I and II) OC. Immediately following cytoreductive surgery, all specimens were analysed with the ATP-based tumour chemosensitivity assay (ATP-TCA) as described previously (7). These specimens were graded according to the National Comprehensive Cancer Network guidelines (22). Routine histopathological analysis was performed for samples obtained from the same tissues to determine the stage and histological features of the tumour samples simultaneously with ATP-TCA testing. The sensitivities of specimens to PTX, carboplatin (CBP), topotecan, gemcitabine (GEM), docetaxel (TXT), bleomycin, etoposide and 4-hydroperoxycyclophosphamide were examined using an in vitro ATP-TCA procedure, Cancer recurrence was defined according to the current clinical criteria as: Return of cancer following completion of treatment following a period of time during which the cancer was not detected (23). In OC, patients with platinum-sensitive cancer were those who achieved complete remission and experienced relapse at 6 months or later following initial platinum-based chemotherapy, whereas patients with platinum-resistant cancer were those who exhibited recurrence within 6 months (24).
Western blot analysis. Total cell lysates were prepared using radioimmunoprecipitation assay lysis buffer (Beyotime Institute of Biotechnology, Shanghai, China) and the supernatant was collected via centrifugation at $4^{\circ} \mathrm{C}$ and $4,024 \mathrm{x}$ g for $10 \mathrm{~min}$. A bicinchoninic acid assay was used to determine the protein concentration. Aliquots (30-40 $\mu \mathrm{l})$ of cell lysates were heated at $100^{\circ} \mathrm{C}$ for $5 \mathrm{~min}$, and $10 \mu \mathrm{g}$ of protein was loaded into each well of a $10 \%$ SDS-PAGE gel for electrophoresis. The proteins on the electrophoresis gel were then transferred to an Immobilon-P membrane that was incubated in blocking solution $[5 \%$ bovine serum albumin (Beijing Dingguo Changsheng Biotechnology Co., Ltd.) in TBS-Tween 20] for $1-3 \mathrm{~h}$ at $25^{\circ} \mathrm{C}$ followed by overnight incubation at $4^{\circ} \mathrm{C}$ with mouse monoclonal anti-human CD105, CD44 and CD106 antibodies at dilutions of 1:1,000. Subsequent to washing 3 times in TBS with $0.1 \%$ Tween 20 , the membrane was incubated for $1-2 \mathrm{~h}$ at $25^{\circ} \mathrm{C}$ with a fluorophore-conjugated secondary antibody (cat. no. 610-132-121; Rockland Immunochemicals, Inc., Limerick, PA, USA) at a dilution of 1:5,000. The membrane was washed and analysed using an Odyssey two-colour infrared imaging system (LICOR Odyssey, LI-COR Biosciences, Lincoln, NE, USA). The signal intensity of protein bands was calculated using Image J software (v1.8.0; National Institutes of Health, Bethesda, MD, USA).

Statistical analysis. Data are presented as the mean \pm standard deviation and were analysed using SPSS v.17.0 for Windows software (SPSS Inc., Chicago, IL, USA). Means were compared using a two-sided t-test. Linear regression analysis was used to detect the correlation between sensitivity index (SI) and expression levels of target genes. All experiments were independently repeated a minimum of three times. $\mathrm{P} \leq 0.05$ was considered to indicate a statistically significant difference. 

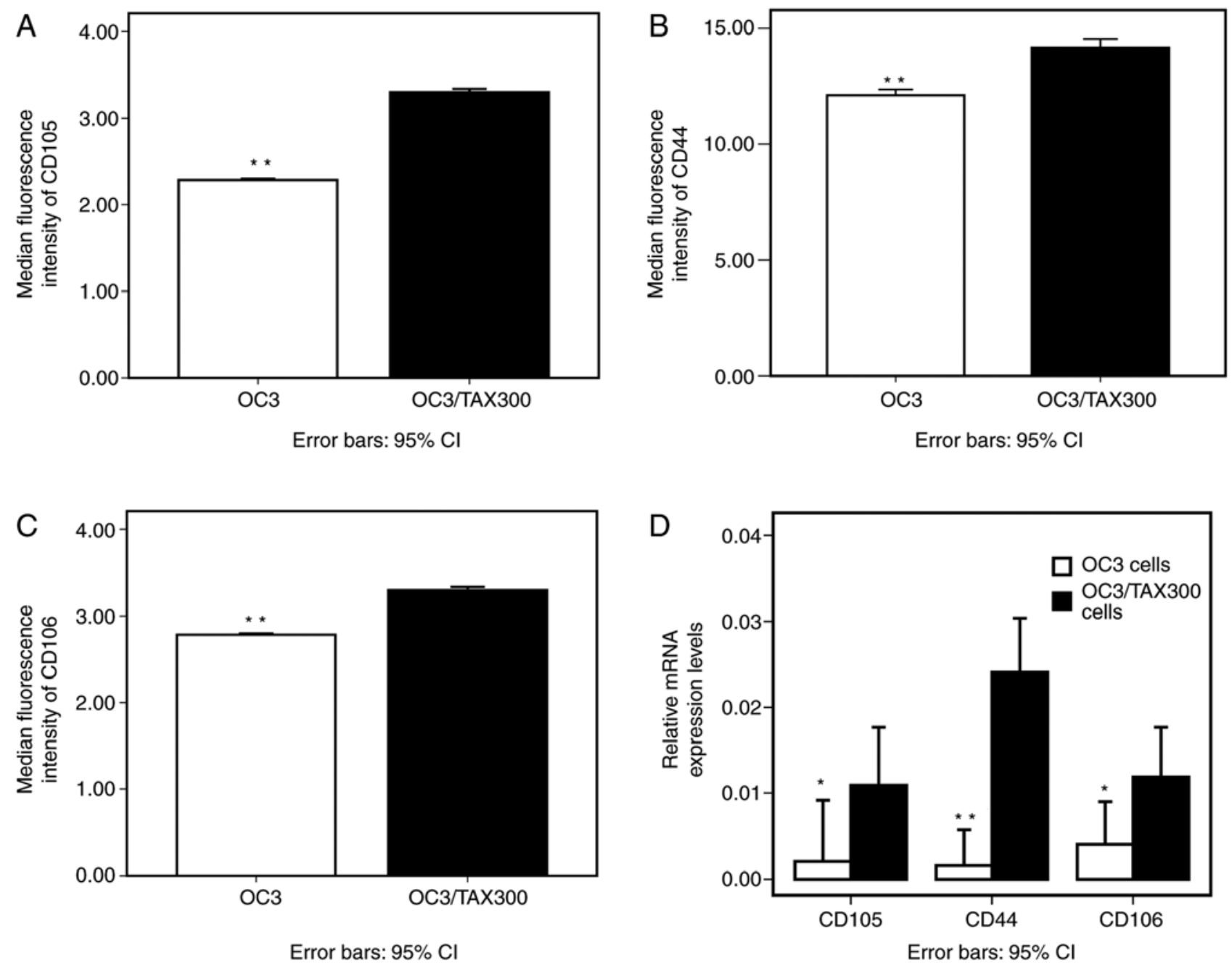

Figure 2. Median fluorescence intensity of CD105, CD44 and CD106 in PTX-resistant OC3/TAX300 and PTX-sensitive OVCAR3 cells, as determined by flow cytometry. (A-C) (A) CD105, (B) CD44 and (C) CD106 overexpression in OC3/TAX300 cells. (D) Relative mRNA expression levels of CD105, CD44 and CD106 in OC3/TAX300 cells. " $\mathrm{P}<0.05$ and ${ }^{* *} \mathrm{P}<0.01$. PTX, paclitaxel; CD44, CD44 antigen; CD105, endoglin; CD106, vascular cell adhesion molecule 1; PTX, paclitaxel; CI, confidence interval.

\section{Results}

CD105, CD44 and CD106 are overexpressed in PTX-resistant $O C$ cells. The percentage of cells positive for the 3 proteins was increased in the PTX-resistant cell line compared with the PTX-sensitive cell line $(\mathrm{P}<0.01$; Fig. 1). Accordingly, the median fluorescence intensities of CD105, CD44 and CD106 were increased in OC3/TAX300 cells compared with the OVCAR3 cells $(\mathrm{P}<0.01$; Fig. 2A-C). The results from the RT-qPCR analysis demonstrated a similar trend to those obtained by flow cytometry, with increased relative expression levels of CD105, CD44 and CD106 mRNA in the OC3/TAX300 cells compared with the OVCAR3 cells ( $\mathrm{P}<0.05$; Fig. 2D).

PTX-resistant OC cells exhibit increased invasive capabilities. The Transwell assay revealed that numerous OC cells had invaded the membrane filter (Fig. 3A and B). The numbers of invaded cells in 12 different fields of vision were counted after $24 \mathrm{~h}$ culture, and the quantitative analysis indicated that the number of invaded cells was increased in the OC3/TAX300 group compared with the OVCAR3 group $(54.7 \pm 6.65$ vs. 31.8 \pm 6.55 ; $\mathrm{P}<0.01$; Fig. $3 \mathrm{C}$ ).
CD105, CD44 and CD106 are highly expressed in drug-resistant epithelial OC tissue samples. In the western blot analysis, the protein expression levels of CD105, CD44 and CD106 in 80 epithelial ovarian cancer tissues were markedly different. This may be associated with the heterogeneity of chemotherapy treatments in patients (7). It was identified that $66 / 80$ were PTX-sensitive and 14/80 were PTX-resistant; and 47/80 were CBP-sensitive and 33/80 were CBP-resistant (Table I). The difference of protein expression in chemoresistant or -sensitive samples was demonstrated by the following: CD105, CD44 and CD106 were expressed at high and low levels in PTX-resistant and PTX-sensitive tissue samples, respectively (Fig. 4A). Statistical analysis of the data demonstrated the significant difference: Protein expression of CD105 was different in 80 specimens with different sensitivity to 8 drugs, and there were increased protein expression levels of CD105 in PTX/CBP/TXT resistant samples compared with sensitive specimens (Fig. 4B). There was an increased protein expression level of CD44 in PTX resistant samples compared with sensitive specimens (Fig. 4C). Among patients exhibiting chemoresistance or sensitivity to the commonly used chemotherapy drugs 
Table I. Results of chemosensitivity assay in OC samples.

\begin{tabular}{|c|c|c|c|c|}
\hline Drug & Sensitivity, n (\%) & Weak sensitivity, n (\%) & Resistance, n (\%) & Sensitivity (\%) \\
\hline PTX & $44(55)$ & $22(27.5)$ & $14(17.5)$ & 82.5 \\
\hline CBP & $21(26.4)$ & $26(32.4)$ & $33(41.2)$ & 58.8 \\
\hline TPT & $14(17.5)$ & $23(28.7)$ & $43(53.8)$ & 46.2 \\
\hline TXT & $18(22.5)$ & $18(22.5)$ & $44(55)$ & 45 \\
\hline GEM & $13(16.3)$ & $13(16.3)$ & $54(67.5)$ & 32.5 \\
\hline $4-\mathrm{HC}$ & $3(3.7)$ & $18(22.5)$ & $59(73.8)$ & 26.2 \\
\hline VP-16 & $4(6.3)$ & $10(11.2)$ & $66(82.5)$ & 17.5 \\
\hline BLM & 0 & 0 & $80(100)$ & 0 \\
\hline
\end{tabular}

PTX, paclitaxel; CBP, carboplatin; TPT, topotecan; TXT, docetaxel; GEM, gemcitabine; 4-HC, 4-hydroperoxycyclophosphamide; VP-16, etoposide; BLM, bleomycin.

A

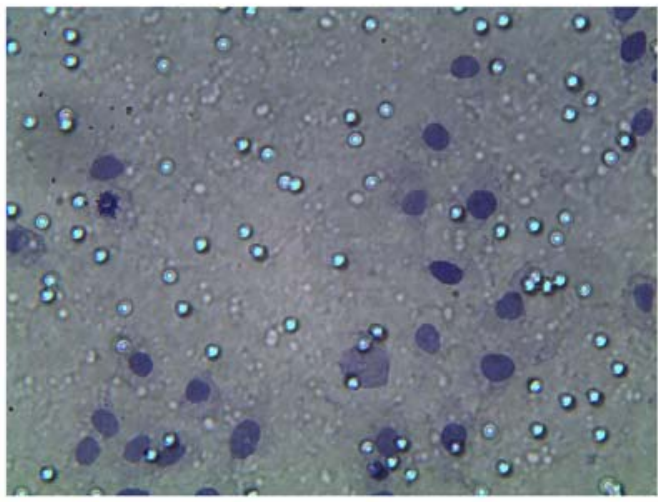

B

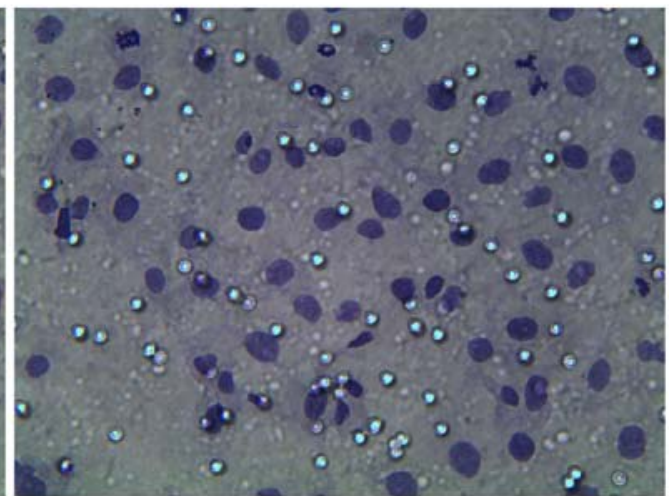

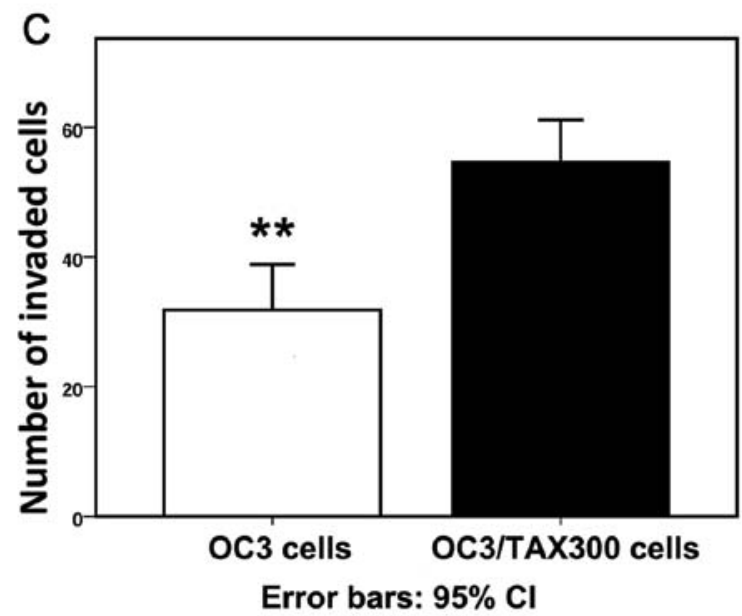

Figure 3. Detection of invasive tumour cells using the Transwell assay. A number of OC cells had invaded the membrane filter. (A) OVCAR3 cells (B) OC3/TAX300 cells. (C) The number of invaded cells was increased in the OC3/TAX300 group compared with the OVCAR3 group. ${ }^{* *} \mathrm{P}<0.01$. OC, ovarian cancer; CI, confidence interval.

including PTX, CBP or TXT, CD106 levels were increased in the chemoresistance group compared with the chemosensitive group (Fig. 4D).

In our previous study, the SI was used to evaluate drug sensitivity rates and was calculated using the formula: $\mathrm{SI}=500-\%$ tumour growth inhibition at 200, 100, 50, 25 and $12.5 \%+$ test drug concentration (7). The expression levels of these target genes in the tissue samples were associated with the SI of a number of the drugs examined; for example, the CD105 level was correlated with the SI value of PTX and TXT (Table II).

CD105, CD44 and CD106 expression levels are associated with clinical parameters of epithelial OC. Moderately and highly differentiated OC tissue samples exhibited decreased CD105 protein expression compared with those 

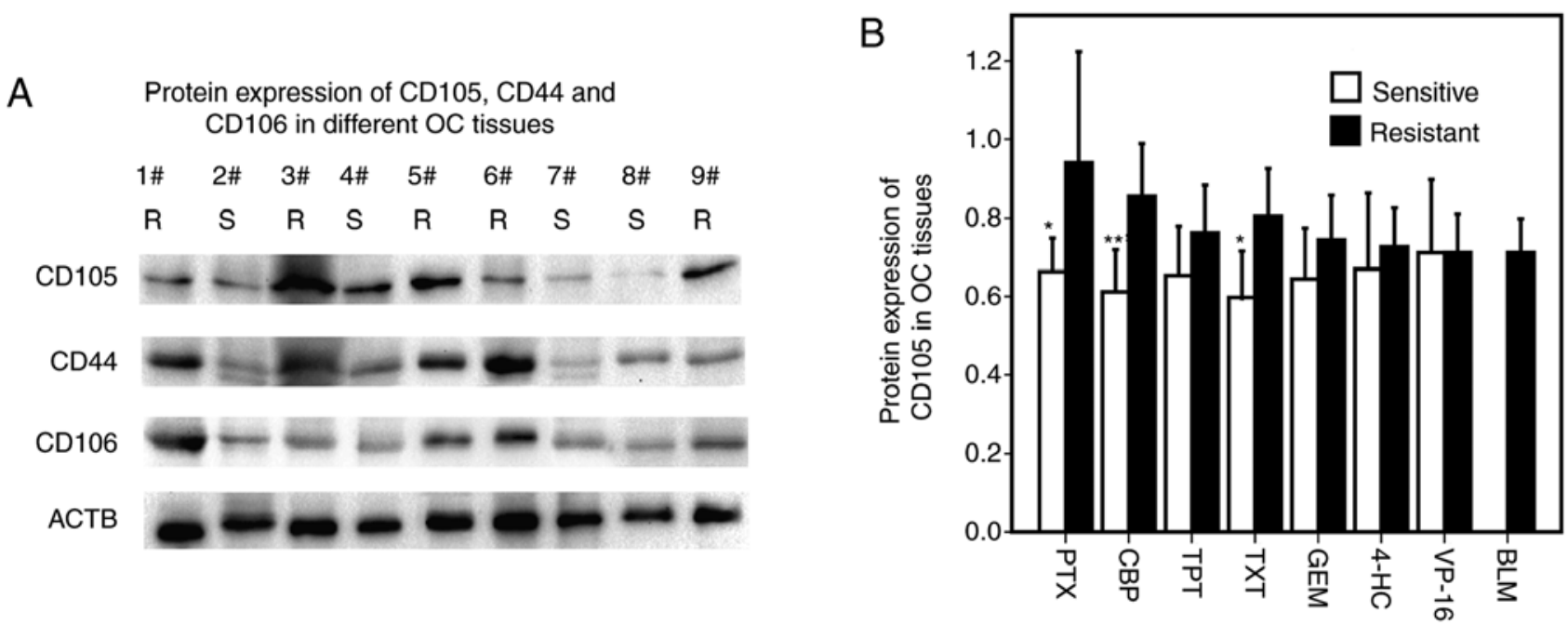

Error bars: $95 \% \mathrm{Cl}$
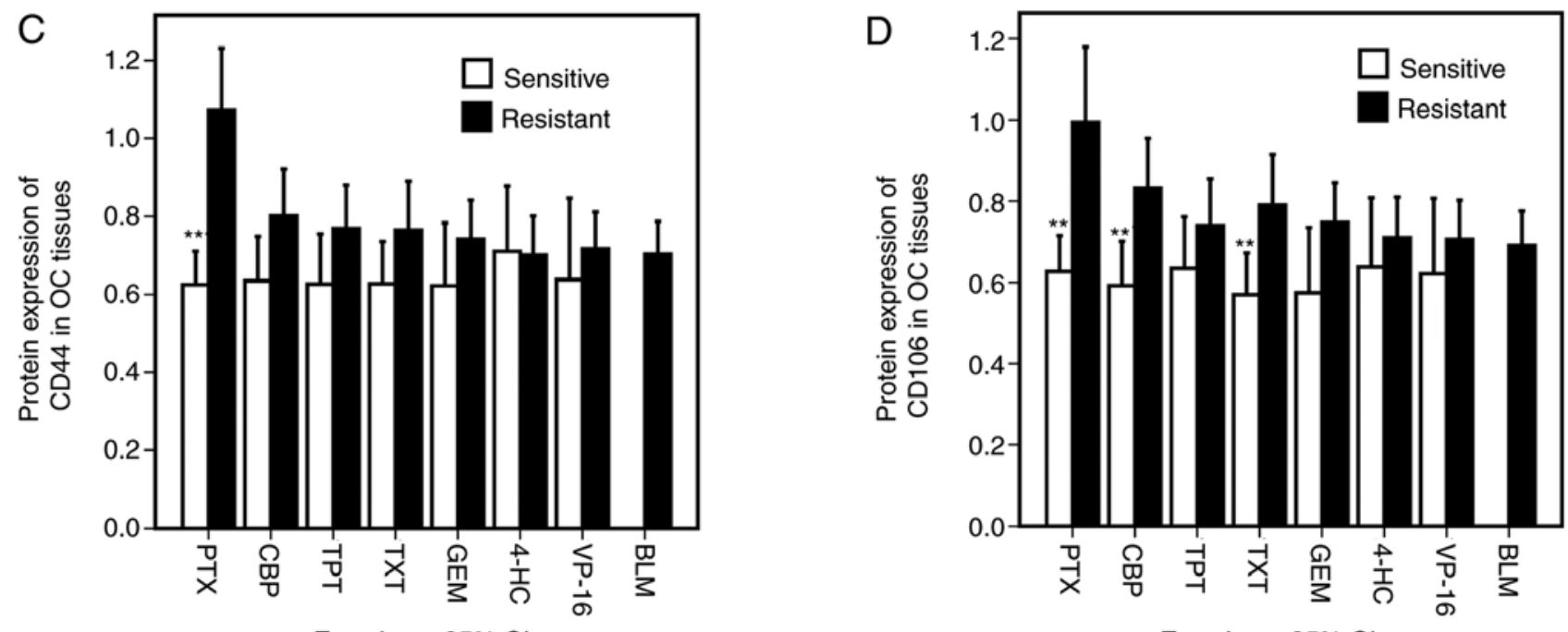

Error bars: $95 \% \mathrm{Cl}$

Figure 4. CD105, CD44 and CD106 are highly expressed in drug-resistant epithelial OC tissue samples. (A) Representative blots of 3 experiments of PTX-resistant and PTX-sensitive samples were subjected to western blot analysis for CD105, CD44 and CD106 protein levels. ACTB was used as a loading control. Each number corresponds to a different patient. CD105, CD44 and CD106 were expressed at high and low levels in PTX-resistant and PTX-sensitive tissue samples, respectively. (B) Difference of expression of CD105 protein in all specimens with different sensitivities to 8 drugs. There were increased protein expression levels of CD105 in PTX/CBP/TXT resistant samples. (C) Difference of expression of CD44 protein in all specimens with different sensitivity to 8 drugs. There was an increased protein expression level of CD44 in PTX resistant samples compared with the sensitive specimens. (D) Difference of expression of CD106 protein in all specimens with different sensitivity to 8 drugs. There were increased protein expression levels of CD106 in PTX/CBP/TXT resistant samples compared with the sensitive specimens. ${ }^{*} \mathrm{P}<0.05$ and ${ }^{* *} \mathrm{P}<0.01$. CD44, CD44 antigen; CD105, endoglin; CD106, vascular cell adhesion molecule 1; BLM, bleomycin; CBP, carboplatin; GEM, gemcitabine; PTX, paclitaxel; TPT, topotecan; TXT, docetaxel; VP-16, etoposide; 4-HC, 4-hydroperoxycyclophosphamide; R, PTX-resistant samples; S, PTX-sensitive samples; ACTB, $\beta$-actin; CI, confidence interval; OC, ovarian cancer.

Table II. Results of correlation analysis between expression levels of target genes and sensitivity index of tested chemotherapy drugs.

\begin{tabular}{lcc}
\hline Drug combination & Correlation coefficient, $r$ & P-value \\
\hline CD105 and PTX & 0.327 & 0.003 \\
CD105 and TXT & 0.285 & 0.010 \\
CD44 and PTX & 0.353 & 0.001 \\
CD106 and PTX & 0.344 & 0.002 \\
CD106 and TXT & 0.321 & 0.004 \\
\hline
\end{tabular}

CD105, endoglin; CD44, CD44 antigen; CD106, vascular cell adhesion molecule 1; PTX, paclitaxel; TXT, docetaxel. that were poorly differentiated $(\mathrm{P}=0.002)$. Furthermore, CD105 expression was decreased at the early stage (I and II) compared with the advanced stage (III) tissues $(\mathrm{P}=0.019)$ and decreased in the primary tumour samples compared with the recurrent ovarian epithelial cancer specimens $(\mathrm{P}=0.006)$. Similar trends were observed for CD44 and CD106 expression (Fig. 5A-C).

All of the cases in the present study were followed up for at least 2 years after initial chemotherapy. A total of 44 patients $(55 \%)$ were classified as clinically CBP-sensitive and $36(45 \%)$ were clinically CBP-resistant. Clinically CBP-sensitive OC tissue samples exhibited decreased CD105 and CD106 expression compared with the resistant cases (Fig. 5D). 
A
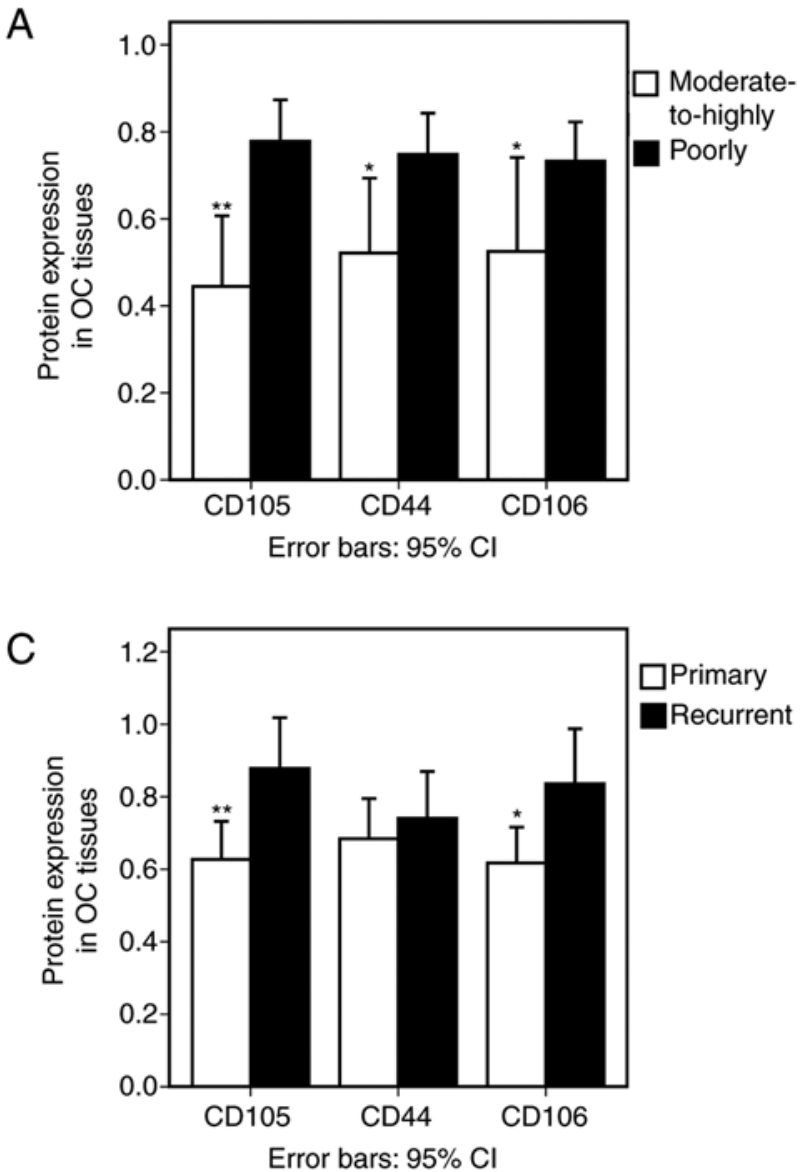
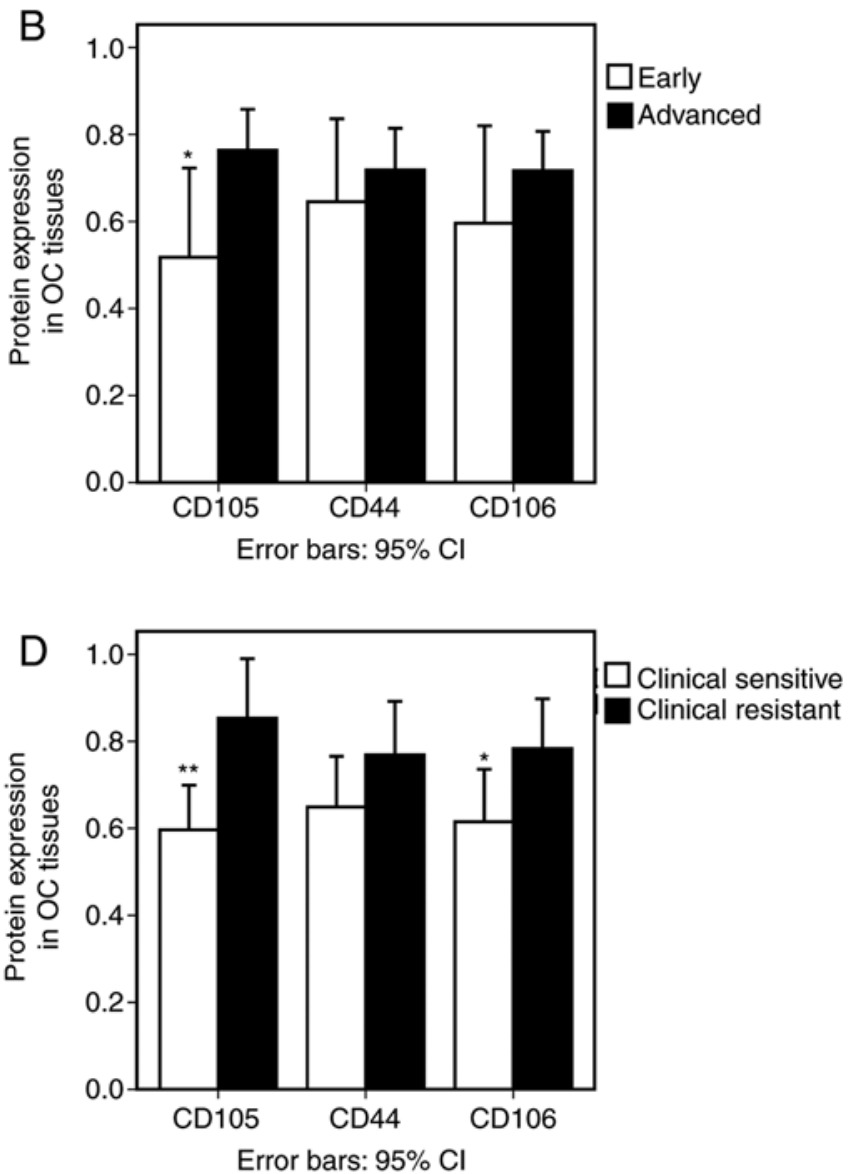

Figure 5. CD105, CD44 and CD106 expression levels are associated with clinical parameters of epithelial OC. (A) Moderately and highly differentiated OC tissue samples exhibited decreased CD105, CD44, and CD106 protein expression compared with poorly differentiated samples. (B) Early-stage (I and II) OC tissue samples exhibited decreased CD105 protein expression compared with advanced-stage (III) samples. (C) Primary OC tissue samples exhibited decreased CD105 and CD106 protein expression compared with recurrent OC tissue samples. (D) Clinically CBP-sensitive ovarian epithelial cancer tissues exhibited decreased CD105 and CD106 expression compared tissues that were clinically CBP-resistant. ${ }^{*} \mathrm{P}<0.05$ and ${ }^{* *} \mathrm{P}<0.01$. CD44, CD44 antigen; CD105, endoglin; CD106, vascular cell adhesion molecule 1; OC, ovarian cancer; CBP, carboplatin; CI, confidence interval.

\section{Discussion}

The present study investigated the association between the expression of the SC markers CD105, CD44 and CD106 and the invasive capabilities and chemotherapeutic resistance of OC cell lines. It was identified that all 3 proteins were overexpressed in PTX-resistant OC3/TAX300 cells and in chemoresistant and poorly differentiated or advanced-stage epithelial OC tissues, and that this was associated with enhanced invasive capacity. These data suggest that exposure to high doses of PTX enhances the SC properties of ovarian tumour cells (including CD105, CD44 and CD106 overexpression), leading to the development of PTX resistance, increased invasion and long-distance metastasis, and poor prognosis in OC.

CD105 is a co-receptor for transforming growth factor (TGF)- $\beta$ family proteins including TGF- $\beta 1$ and $-\beta 3$, and serves a key role in development, cell proliferation, extracellular matrix synthesis, angiogenesis and the immune response (25). CD105 exhibits SC characteristics and may stimulate endothelial cell growth; its high level of expression on peri- and intratumoural vessels is associated with poor prognosis following cancer treatment (26-28). CD105 overexpression has also been identified to be associated with decreased patient survival rates and distant metastasis (27-30); this is likely due to the angiogenesis-promoting function of CD105, which has been demonstrated to increase tumour vasculature and ultimately lead to poor prognosis (31-33).

CD105 is expressed not only in vascular endothelial cells, but it is also detected in several malignancies including gastrointestinal stromal tumours, hepatocellular carcinoma, and breast cancer (34-36), head and neck paragangliomas (37), and OC ascites (38). Furthermore, CD105-expressing cells have multi-differentiation potential: CD105-positive rhabdoid meningioma cells exhibit SC-like features and have the capacity to differentiate into adipocytes and osteocytes (39).

Various studies have demonstrated that CD105 overexpression is associated with chemoresistance. CD105 is rarely detected in primary OC cells, but is expressed at an increased level in platinum-resistant cells compared with primary untreated tumour cells (2). Notably, the protein is predominantly localised in the cytoplasm, which is consistent with the features of a CSC-like population. CD105 inhibition increases cisplatin sensitivity and decreases OC cell viability while enhancing apoptosis via induction of double-stranded DNA damage (40). It has also been suggested that chemotherapy stimulates CD90 and CD105 expression in hepatocellular carcinoma cells (41). These studies suggest that poor prognosis in cancer is not solely 
due to the induction of tumour angiogenesis by CD105 (42), but that it is also caused by CD105 overexpression in tumour cells. Accordingly, CD105 has been investigated as a potential therapeutic target: One study identified that downregulation of CD105 decreased tumourigenicity and GEM resistance, suggesting that CD105 expression not only distinguishes a CSC subpopulation but also confers self-renewal capacity and contributes to chemoresistance in renal cell carcinoma (43). Additionally, the anti-CD105 antibody TRC105 inhibited tumour growth and improved survival without off-target toxicity in a mouse model of mammary carcinoma (44), with similar results demonstrated in acute leukaemia (45). A previous clinical study that enrolled 26 patients with hepatocellular carcinoma showed that TRC105 combined with sorafenib was well tolerated at the recommended single agent doses of both drugs (46), and another clinical trial that enrolled 13 patients with urothelial carcinoma also found TRC105 was well tolerated, although the benefits of extended survival of patients need further examination (47).

CD106, also known as vascular cell adhesion molecule 1 , is a member of the immunoglobulin superfamily of transmembrane proteins that bind integrin (48). CD106 mediates leukocyte adhesion to endothelial cells and downstream signalling cascades (49), and serves an important role in the oncogenesis, tumour angiogenesis, tumour progression, and metastasis of human cancer (50) including colorectal carcinoma (51), non-Hodgkin lymphoma (52) and gastric carcinoma (53). CD106 is highly expressed in OC (54), has been associated with ovarian tumour growth, and may be a prognostic indicator and potential therapeutic target (16). CD106 was also demonstrated to be overexpressed in breast cancer (55) and enhances breast cancer cell metastasis to the lungs (56). It has previously been demonstrated that CD106 is highly overexpressed in lung cancer compared with normal lung tissue, and that it is associated with poor survival. Additionally, the invasive potential of lung cancer cells is significantly weakened by CD106 silencing (57).

CD44 is a classic surface marker of SCs, which promotes oncogenesis and tumour progression (58). Cells with this phenotype are more likely to form tumours compared with those with alternate phenotypes. A number of studies have suggested that CD44 is a reliable cell surface marker for CSCs in gastric (59) and breast cancer (60), glioma (61), colon cancer (62) and OC (11). High CD44 expression is associated with metastasis, recurrence, chemoresistance and survival rate in $\mathrm{OC}$, whereas its downregulation suppresses tumour cell proliferation and metastasis and reverses chemoresistance (63). The present study demonstrated that OC cells expressing CD105, CD44 and CD106 on their surface exhibited greater invasive capabilities and drug resistance. Although the results are consistent with the earlier studies, additional studies are required to determine whether targeting these factors would be effective for the treatment of OC.

In conclusion, the results from the present study demonstrated that CD105, CD44 and CD106 were upregulated in PTX-resistant OC cell lines and chemoresistant epithelial OC tissues. This was associated with poor prognosis, distant metastasis and early recurrence. At present, these results have certain limitations, as they are only based on a PTX-resistant OC cell line and its primary parent cell line, and also require validation by knocking down CD105, CD44 or CD106 genes. However, these positive results suggested future avenues of study, and other PTX or platinum resistant cell lines will be examined in subsequent experiments, and CD105 gene knockdown will be performed to study the changes of invasiveness of OC3/TAX300 cells following inhibition of the expression of CD105 gene and the tumourigenicity in nude mice. Therefore, inhibiting CD105, CD44 or CD106 expression has potential as an adjuvant therapy for OC. Additionally, as these factors confer SC characteristics, investigating other CSCs markers may provide a basis for targeted therapy and for predicting patient prognosis.

\section{Acknowledgements}

Not applicable.

\section{Funding}

The present study was supported by the Hospital Subject of Beijing Shijitan Hospital, Capital Medical University (Beijing, China: Grant no. 2014-C16).

\section{Availability of data and materials}

The datasets used and/or analysed during the present study are available from the corresponding author on reasonable request.

\section{Authors' contributions}

JZ, BY and HZ performed the experiments. JZ and HL performed the statistical analysis and wrote the manuscript.

\section{Ethics approval and consent to participate}

The present study was approved by the Ethics Committee of the Beijing Shijitan Hospital of Capital Medical University (Beijing, China). Written informed consent was obtained from all participants prior to surgery. All procedures were performed in accordance with the Declaration of Helsinki.

\section{Patient consent for publication}

Written informed consent was obtained from all participants prior to surgery.

\section{Competing interests}

The authors declare that they have no competing interests.

\section{References}

1. Jemal A, Siegel R, Xu J and Ward E: Cancer statistics, 2010. CA Cancer J Clin 60: 277-300, 2010.

2. Steg AD, Bevis KS, Katre AA, Ziebarth A, Dobbin ZC, Alvarez RD, Zhang K, Conner M and Landen CN: Stem cell pathways contribute to clinical chemoresistance in ovarian cancer. Clin Cancer Res 18: 869-881, 2012.

3. Rosen JM and Jordan CT: The increasing complexity of the cancer stem cell paradigm. Science 324: 1670-1673, 2009.

4. Dalerba P, Cho RW and Clarke MF: Cancer stem cells: Models and concepts. Annu Rev Med 58: 267-284, 2007.

5. Hsieh CH, Hsiung SC, Yeh CT, Yen CF, Chou YW, Lei WY, Pang ST, Chuang CK and Liao SK: Differential expression of CD44 and CD24 markers discriminates the epithelioid from the fibroblastoid subset in a sarcomatoid renal carcinoma cell line: Evidence suggesting the existence of cancer stem cells in both subsets as studied with sorted cells. Oncotarget 8: 15593-15609, 2017. 
6. Zhang XF, Weng DS, Pan K, Zhou ZQ, Pan QZ, Zhao JJ, Tang Y, Jiang SS, Chen CL, Li YQ, et al: Dendritic-cell-based immunotherapy evokes potent anti-tumor immune responses in CD105+ human renal cancer stem cells. Mol Carcinog 56: 2499-2511, 2017.

7. Zhang $\mathrm{J}$ and $\mathrm{Li} \mathrm{H}$ : Heterogeneity of tumor chemosensitivity in ovarian epithelial cancer revealed using the adenosine triphosphate-tumor chemosensitivity assay. Oncol Lett 9: 2374-2380, 2015.

8. Muinao T, Deka Boruah HP and Pal M: Diagnostic and prognostic biomarkers in ovarian cancer and the potential roles of cancer stem cells-An updated review. Exp Cell Res 362: 1-10, 2018

9. Alvero AB, Montagna MK, Holmberg JC, Craveiro V, Brown DA and Mor G: Targeting the mitochondria activates two independent cell death pathways in the ovarian cancer stem cells. Mol Cancer Ther 10: 1385-1393, 2011

10. Slomiany MG, Dai L, Tolliver LB, Grass GD, Zeng Y and Toole BP: Inhibition of functional hyaluronan-CD44 interactions in CD133-positive primary human ovarian carcinoma cells by small hyaluronan oligosaccharides. Clin Cancer Res 15: 7593-7601, 2009

11. Bartakova A, Michalova K, Presl J, Vlasak P, Kostun J and Bouda J: CD44 as a cancer stem cell marker and its prognostic value in patients with ovarian carcinoma. J Obstet Gynaecol 38 110-114, 2018.

12. Ho CM, Chang SF, Hsiao CC, Chien TY and Shih DT: Isolation and characterization of stromal progenitor cells from ascites of patients with epithelial ovarian adenocarcinoma. J Biomed Sci 19: 23, 2012.

13. Bussolati B, Bruno S, Grange C, Ferrando U and Camussi G: Identification of a tumor-initiating stem cell population in human renal carcinomas. FASEB J 22: 3696-3705, 2008.

14. Yang ZX, Han ZB, Ji YR, Wang YW, Liang L, Chi Y, Yang SG, Li LN, Luo WF, Li JP, et al: CD106 identifies a subpopulation of mesenchymal stem cells with unique immunomodulatory properties. PLoS One 8: e59354, 2013.

15. Kokovay E, Wang Y, Kusek G, Wurster R, Lederman P, Lowry N, Shen Q and Temple S: VCAM1 is essential to maintain the structure of the SVZ niche and acts as an environmental sensor to regulate SVZ lineage progression. Cell Stem Cell 11: 220-230, 2012.

16. Huang J, Zhang J, Li H, Lu Z, Shan W, Mercado-Uribe I and Liu J: VCAM1 expression correlated with tumorigenesis and poor prognosis in high grade serous ovarian cancer. Am J Transl Res 5: 336-346, 2013.

17. Zhang J, Zhao J, Zhang W, Liu G, Yin D, Li J, Zhang S and Li H: Establishment of paclitaxel-resistant cell line and the underlying mechanism on drug resistance. Int J Gynecol Cancer 22: $1450-1456,2012$

18. Zhang L, Liu P, Li H and Xue F: Effect of histone deacetylase inhibitors on cell apoptosis and expression of the tumor suppressor genes RUNX3 and ARHI in ovarian tumors. Mol Med Rep 7: 1705-1709, 2013.

19. Zhang J, Yin D and Li H: hMSH2 expression is associated with paclitaxel resistance in ovarian carcinoma, and inhibition of hMSH2 expression in vitro restores paclitaxel sensitivity. Oncol Rep 32: 2199-2206, 2014

20. Benson DA, Cavanaugh M, Clark K, Karsch-Mizrachi I, Lipman DJ, Ostell J and Sayers EW: GenBank. Nucleic Acids Res 41 (Database Issue): D36-D42, 2013.

21. Livak KJ and Schmittgen TD: Analysis of relative gene expression data using real-time quantitative PCR and the 2(-Delta Delta C(T)) method. Methods 25: 402-408, 2001.

22. Daly MB, Pilarski R, Berry M, Buys SS, Farmer M, Friedman S, Garber JE, Kauff ND, Khan S, Klein C, et al: NCCN Guidelines insights: Genetic/Familial High-risk assessment: Breast and ovarian, version 2.2017. J Natl Compr Canc Netw 15:9-20, 2017.

23. Ozga M, Aghajanian C, Myers-Virtue S, McDonnell G, Jhanwar S, Hichenberg S and Sulimanoff I: A systematic review of ovarian cancer and fear of recurrence. Palliat Support Care 13: $1771-1780,2015$

24. Fung-Kee-Fung M, Oliver T, Elit L, Oza A, Hirte HW and Bryson P: Optimal chemotherapy treatment for women with recurrent ovarian cancer. Curr Oncol 14: 195-208, 2007.

25. Barbara NP, Wrana JL and Letarte M: Endoglin is an accessory protein that interacts with the signaling receptor complex of multiple members of the transforming growth factor-beta superfamily. J Biol Chem 274: 584-594, 1999.

26. Nassiri F, Cusimano MD, Scheithauer BW, Rotondo F, Fazio A, Yousef GM, Syro LV, Kovacs K and Lloyd RV: Endoglin (CD105): A review of its role in angiogenesis and tumor diagnosis, progression and therapy. Anticancer Res 31: 2283-2290, 2011.
27. Dallas NA, Samuel S, Xia L, Fan F, Gray MJ, Lim SJ and Ellis LM: Endoglin (CD105): A marker of tumor vasculature and potential target for therapy. Clin Cancer Res 14: 1931-1937, 2008.

28. Taskiran C, Erdem O, Onan A, Arisoy O, Acar A, Vural C, Erdem M, Ataoglu O and Guner $\mathrm{H}$ : The prognostic value of endoglin (CD105) expression in ovarian carcinoma. Int J Gynecol Cancer 16: 1789-1793, 2006.

29. Saad RS, El-Gohary Y, Memari E, Liu YL and Silverman JF: Endoglin (CD105) and vascular endothelial growth factor as prognostic markers in esophageal adenocarcinoma. Hum Pathol 36: 955-961, 2005

30. Chien CY, Su CY, Hwang CF, Chuang HC, Chen CM and Huang CC: High expressions of CD105 and VEGF in early oral cancer predict potential cervical metastasis. J Surg Oncol 94: 413-417, 2006.

31. Cho T, Shiozawa E, Urushibara F, Arai N, Funaki T, Takehara Y, Tazawa S, Misawa M, Homma M, Norose T, et al: The role of microvessel density, lymph node metastasis, and tumor size as prognostic factors of distant metastasis in colorectal cancer. Oncol Lett 13: 4327-4333, 2017.

32. Fonsatti E and Maio M: Highlights on endoglin (CD105): From basic findings towards clinical applications in human cancer. J Transl Med 2: 18, 2004

33. Ding S, Li C, Lin S, Yang Y, Liu D, Han Y, Zhang Y, Li L, Zhou L and Kumar S: Comparative evaluation of microvessel density determined by CD34 or CD105 in benign and malignant gastric lesions. Hum Pathol 37: 861-866, 2006.

34. Gromova P, Rubin BP, Thys A, Cullus P, Erneux C and Vanderwinden JM: ENDOGLIN/CD105 is expressed in KIT positive cells in the gut and in gastrointestinal stromal tumors. J Cell Mol Med 16: 306-317, 2012.

35. Ribeiro OD, Canedo NH and Pannain VL: Immunohistochemical angiogenic biomarkers in hepatocellular carcinoma and cirrhosis: Correlation with pathological features. Clinics (Sao Paulo) 71: 639-643, 2016.

36. Davidson B, Stavnes HT, Førsund M, Berner A and Staff AC: CD105 (Endoglin) expression in breast carcinoma effusions is a marker of poor survival. Breast 19: 493-498, 2010.

37. LitwiniukM,NiemczykK,Niderla-BielińskaJ,Łukawska-PopieluchI and Grzela T: Soluble endoglin (CD105) serum level as a potential marker in the management of head and neck paragangliomas. Ann Otol Rhinol Laryngol 126: 717-721, 2017.

38. Bock AJ, Tuft Stavnes H, Kærn J, Berner A, Staff AC and Davidson B: Endoglin (CD105) expression in ovarian serous carcinoma effusions is related to chemotherapy status. Tumour Biol 32: 589-596, 2011.

39. Hu D, Wang X, Mao Y and Zhou L: Identification of CD105 (endoglin)-positive stem-like cells in rhabdoid meningioma. J Neurooncol 106: 505-517, 2012.

40. Ziebarth AJ, Nowsheen S, Steg AD, Shah MM, Katre AA, Dobbin ZC, Han HD, Lopez-Berestein G, Sood AK, Conner M, et al: Endoglin (CD105) contributes to platinum resistance and is a target for tumor-specific therapy in epithelial ovarian cancer. Clin Cancer Res 19: 170-182, 2013.

41. Nomura Y, Yamashita T, Oishi N, Nio K, Hayashi T, Yoshida M, Hayashi T, Hashiba T, Asahina Y, Okada H, et al: De novo emergence of mesenchymal stem-like CD105+ cancer cells by cytotoxic agents in human hepatocellular carcinoma. Transl Oncol 10: 184-189, 2017

42. Minhajat R, Mori D, Yamasaki F, Sugita Y, Satoh T and Tokunaga O: Organ-specific endoglin (CD105) expression in the angiogenesis of human cancers. Pathol Int 56: 717-723, 2006.

43. Hu J, Guan W, Liu P, Dai J, Tang K, Xiao H, Qian Y, Sharrow AC, $\mathrm{Ye} \mathrm{Z}, \mathrm{Wu} \mathrm{L}$ and $\mathrm{Xu} \mathrm{H}$ : Endoglin is essential for the maintenance of self-renewal and chemoresistance in renal cancer stem cells. Stem Cell Rep 9: 464-477, 2017.

44. Ehlerding EB, Lacognata S, Jiang D, Ferreira CA, Goel S, Hernandez R, Jeffery JJ, Theuer CP and Cai W: Targeting angiogenesis for radioimmunotherapy with a ${ }^{177} \mathrm{Lu}$-labeled antibody. Eur J Nucl Med Mol Imaging 45: 123-131, 2018.

45. Dourado KMC, Baik J, Oliveira VKP, Beltrame M, Yamamoto A, Theuer CP, Figueiredo CAV, Verneris MR and Perlingeiro RCR: Endoglin: A novel target for therapeutic intervention in acute leukemias revealed in xenograft mouse models. Blood 129: 2526-2536, 2017

46. Duffy AG,Ma C,Ulahannan SV,Rahma OE, Makarova-Rusher O, Cao L, Yu Y, Kleiner DE, Trepel J, Lee MJ, et al: Phase I and preliminary phase II study of TRC105 in combination with sorafenib in hepatocellular carcinoma. Clin Cancer Res 23: 4633-4641, 2017 
47. Apolo AB, Karzai FH, Trepel JB, Alarcon S, Lee S, Lee MJ, Tomita Y, Cao L, Yu Y, Merino MJ, et al: A phase II clinical trial of TRC105 (anti-endoglin antibody) in adults with advanced/metastatic urothelial carcinoma. Clin Genitourin Cancer 15: 77-85, 2017.

48. Malhotra S and Kincade PW: Canonical Wnt pathway signaling suppresses VCAM-1 expression by marrow stromal and hematopoietic cells. Exp Hematol 37: 19-30, 2009.

49. Yamada Y, Arao T, Matsumoto K, Gupta V, Tan W, Fedynyshyn J, Nakajima TE, Shimada Y, Hamaguchi T, Kato K, et al: Plasma concentrations of VCAM-1 and PAI-1: A predictive biomarker for post-operative recurrence in colorectal cancer. Cancer Sci 101: 1886-1890, 2010.

50. Yurkovetsky Z, Skates S, Lomakin A, Nolen B, Pulsipher T, Modugno F, Marks J, Godwin A, Gorelik E, Jacobs I, et al: Development of a multimarker assay for early detection of ovarian cancer. J Clin Oncol 28: 2159-2166, 2010.

51. Dymicka-Piekarska V, Guzinska-Ustymowicz K, Kuklinski A and Kemona H: Prognostic significance of adhesion molecules (sICAM-1, sVCAM-1) and VEGF in colorectal cancer patients. Thromb Res 129: e47-e50, 2012.

52. Shah N, Cabanillas F, McIntyre B, Feng L, McLaughlin P, Rodriguez MA, Romaguera J, Younes A, Hagemeister FB, Kwak L and Fayad L: Prognostic value of serum CD44, intercellular adhesion molecule-1 and vascular cell adhesion molecule-1 levels in patients with indolent non-Hodgkin lymphomas. Leuk Lymphoma 53: 50-56, 2012.

53. Ding YB, Chen GY, Xia JG, Zang XW, Yang HY and Yang L: Association of VCAM-1 overexpression with oncogenesis, tumor angiogenesis and metastasis of gastric carcinoma. World J Gastroenterol 9: 1409-1414, 2003.

54. Slack-Davis JK, Atkins KA, Harrer C,Hershey ED and Conaway M: Vascular cell adhesion molecule-1 is a regulator of ovarian cancer peritoneal metastasis. Cancer Res 69: 1469-1476, 2009.

55. Wang PC, Weng CC, Hou YS, Jian SF, Fang KT, Hou MF and Cheng KH: Activation of VCAM-1 and its associated molecule CD44 leads to increased malignant potential of breast cancer cells. Int J Mol Sci 15: 3560-3579, 2014.
56. Chen Q, Zhang XH and Massagué J: Macrophage binding to receptor VCAM-1 transmits survival signals in breast cancer cells that invade the lungs. Cancer Cell 20: 538-549, 2011.

57. Kim MR, Jang JH, Park CS, Kim TK, Kim YJ, Chung J, Shim H, Nam IH, Han J and Lee S: A human antibody that binds to the sixth Ig-like domain of VCAM-1 blocks lung cancer cell migration i n vitro. Int J Mol Sci 18: pii: E566, 2017.

58. Yan Y, Zuo X and Wei D: Concise review: Emerging role of CD44 in cancer stem cells: A Promising biomarker and therapeutic target. Stem Cells Transl Med 4: 1033-1043, 2015.

59. Takaishi S, Okumura T, Tu S, Wang SS, Shibata W, Vigneshwaran R, Gordon SA, Shimada Y and Wang TC: Identification of gastric cancer stem cells using the cell surface marker CD44. Stem Cells 27: 1006-1020, 2009.

60. Hu J, Li G, Zhang P, Zhuang X and Hu G: A CD44v' subpopulation of breast cancer stem-like cells with enhanced lung metastasis capacity. Cell Death Dis 8: e2679, 2017.

61. Pietras A, Katz AM, Ekström EJ, Wee B, Halliday JJ, Pitter KL, Werbeck JL, Amankulor NM, Huse JT and Holland EC: Osteopontin-CD44 signaling in the glioma perivascular niche enhances cancer stem cell phenotypes and promotes aggressive tumor growth. Cell Stem Cell 14: 357-369, 2014.

62. Su YJ, Lai HM, Chang YW, Chen GY and Lee JL: Direct reprogramming of stem cell properties in colon cancer cells by CD44. EMBO J 30: 3186-3199, 2011.

63. Gao Y, Foster R, Yang X, Feng Y, Shen JK, Mankin HJ, Hornicek FJ, Amiji MM and Duan Z: Up-regulation of CD44 in the development of metastasis, recurrence and drug resistance of ovarian cancer. Oncotarget 6: 9313-9326, 2015.

(i) $($ This work is licensed under a Creative Common Attribution-NonCommercial-NoDerivatives 4.0 International (CC BY-NC-ND 4.0) License. 